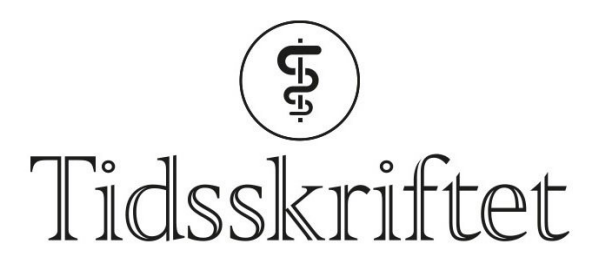

DEN NORSKE LEGEFORENING

\title{
Pågangsmot av en annen verden
}

INTERVJU

TORI FLAATTEN HALVORSEN

E-post: tori.f.halvorsen@gmail.com

Kommunal akutt døgnenhet (KAD-Aker), Oslo kommune

Som fireåring kom hun til Norge sammen med en stor familie. Kun den siste eksamenen på medisinstudiet gjenstod da koronaviruset slo ned og hun måtte ut av Polen. Men ingenting stopper Saido Essa Hamud.

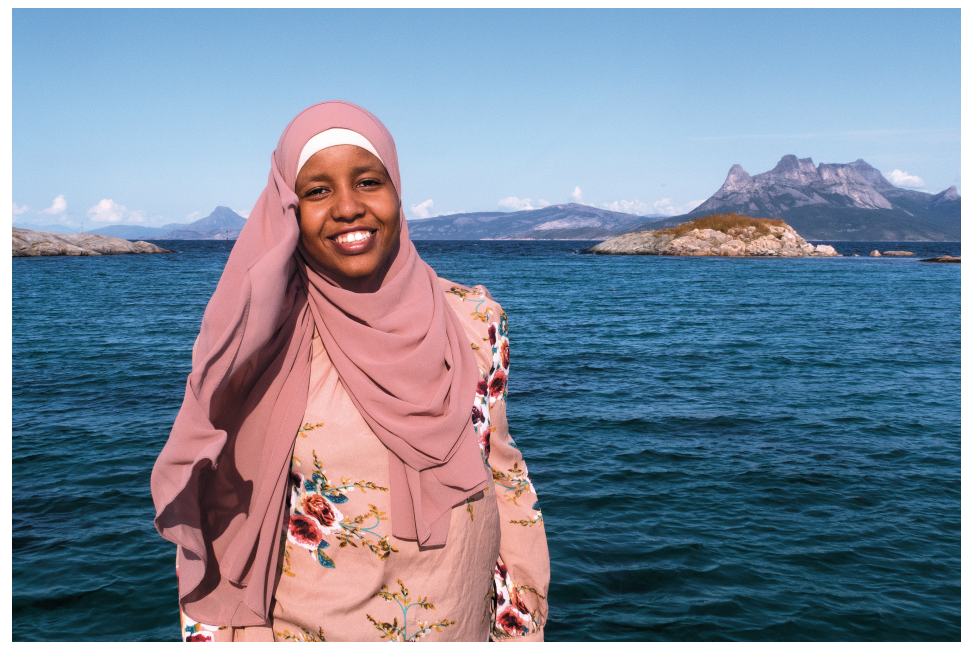

Foto: Tori Flaatten Halvorsen

Saido Essa Hamud gikk i tredje klasse på Halsen barneskole på Stjørdal da hun lovte læreren sin at hun ikke skulle gifte seg før hun var ferdig med seks år på medisinstudiet. Rett etter videregående startet hun på medisinstudier i Polen. I mars i år fikk hun ett døgn på å forlate Białystok. Covid-19 satte en midlertidig stopper for den aller siste eksamenen. Vel hjemme i Trøndelag meldte hun til legekontoret på Hamarøy at hun igjen var i landet. De takket og bukket for at fjorårets sommervikar kunne hjelpe dem i koronaberedskapens tid. Etter 14 dagers karantene var hun igjen på plass i havgapet der nord.

\section{Første sommer som lege}

- Alle liker sommervikarlegen så godt, fortalte helsesykepleieren begeistret da jeg i fjor sommer var innom på mitt tidligere arbeidssted i den vakre Nordlandskommunen Hamarøy. - Hun studerer i Polen og jobber med midlertidig lisens, fortsatte helsesykepleieren.

En pasient kom ut fra kontoret der vikarlegen jobbet. Han hilste blidt. En ung kvinne med hvit bukse, hvit kittel og lyserøde joggesko dukket opp i den samme døra. Den hvite hijaben 
rammet inn det brune og blide ansiktet. Jeg skvatt. Med fast blikk og et kraftig håndtrykk presenterte hun seg.

- Så deilig med is og jordbær. Er det du som har tatt det med? spurte Saido og satte seg ned ved lunsjbordet.

\section{Saido Essa Hamud}

Født 1995

Cand.med. University of Białystok, Polen 2020

Medisinstudent med lisens, Hamarøy legekontor 2019-

Kontaktperson for Norsk medisinstudentforening 2019-2O

Koordinator for NorPal-Sawa 2019

Dagen etter tok Saido og jeg oss en tur i fjæresteinene på Tranøy, det aller vakreste stedet $\mathrm{i}$ kommunen. Jeg spurte om hun hadde oppdaget min forbauselse dagen før.

- Selvfølgelig så jeg det! Men sannheten er at jeg også selv ville ha blitt overrasket. Det er jo først med min generasjon at somaliske kvinner tar legeutdanning. Ja - utdanning i det hele tatt, smilte hun, og så var hun i gang med å fortelle sin historie.

\section{Mogadishu - Stjørdal}

Saido er 24 år. Som fireåring kom hun sammen med mor og ni halv- og helsøsken fra den støvete mangemillionbyen Mogadishu til lille Stjørdal i full vinterdrakt. Den store ungeflokken og moren skulle gjenforenes med faren. Faren var imam og har siden bygget opp en liten moske i Stjørdal. Moren kunne verken lese eller skrive da de kom. Saido forteller stolt at moren nå er i gang med grunnskoleutdanning.

Det er jo først med min generasjon at somaliske kvinner tar legeutdanning. Ja - utdanning i det hele tatt

- Samholdet i familien og blant de andre somalierne i Stjørdal har vært helt avgjørende for at jeg har det så bra, forteller hun mens hun holder på hijaben som blafrer i vinden.

- Og så har skolen vært uvurderlig. Jeg har fortsatt kontakt med alle kontaktlærerne fra skoletiden. For ikke lenge siden fant jeg et håndskrevet brev fra en av dem i postkassen min i Polen. Læreren min skrev at han var så stolt av meg og at han alltid har trodd at jeg skulle nå langt. Det betyr alt!

\section{Avtale om yrkesvalg}

Saido minnes da hun og søsteren lagde en skriftlig avtale om fremtidig yrkesvalg.

- Vi var allerede da så glade for at vi kunne få muligheten til å ta en utdanning. Vi tenkte på alle de i hjemlandet som aldri får den sjansen.

På det tidspunktet gikk jentene på ungdomsskolen. Saido ville bli lege.

- Eller hvordan var det med den avtalen egentlig? Saido nøler og tenker seg om. 


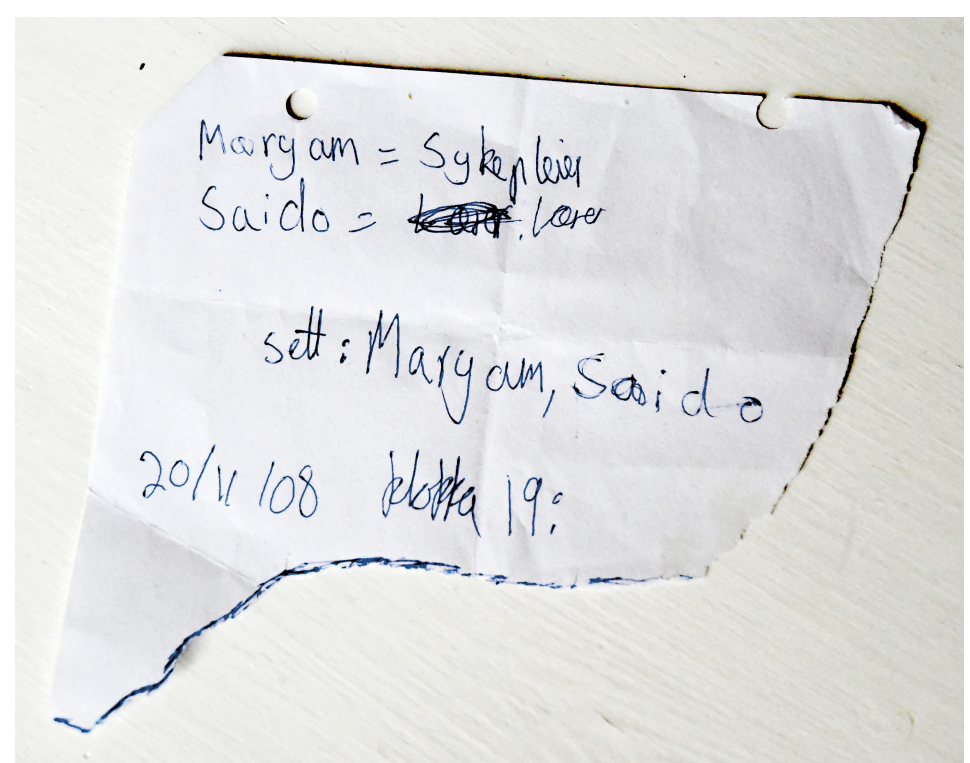

Saido har spart på avtalen hun gjorde med søsteren da de var i starten av tenårene. Drømmen for Saido var å bli lege. Søsteren ville egentlig bli jordmor. For å sikre seg mot å mislykkes lovte de hverandre at de «i alle fall skulle bli lcerer og sykepleier». Tiden har vist at de klarte å bli det de drømte om. Foto: privat

- Drømmene våre var der, men på det tidspunktet var jeg usikker på hva jeg kunne klare. Jeg var også i tvil om det var lov å bruke hijab sammen med legefrakken.

Det endte med at hun først skrev lcerer på avtalen med søsteren. Så krysset hun over det og ville skrive lege. Men allerede før hun igjen ville skrive drømmeyrket ned på den lille lappen, tvilte hun på nytt.

-Så jeg skrev laerer for andre gang. Jeg ville ikke mislykkes.

\section{Støtte fra foreldrene}

- Du hører kanskje at jeg av og til stopper opp midt i en setning?

Jeg innrømmer at det har jeg slett ikke lagt merke til. Det som derimot er slående, er hennes engasjement, åpenhet og fortellerevne, i tillegg til en blid og direkte framtoning.

- Det er kanskje ikke så tydelig lenger, men jeg har lært meg til å stoppe litt opp når jeg kjenner at jeg er i ferd med å begynne å stamme.

Hun opplevde at stammingen har vært et mye større problem enn at hun var jente, fra en kultur der kvinnene tradisjonelt sett ikke har tatt utdanning, at hun aldri har hatt mulighet for leksehjelp hjemme eller at den store søskenflokken har foreldre som naturligvis snakker gebrokkent norsk. At familien hadde dårligere økonomi enn de fleste nordmenn, var heller ikke noe som hun tenkte ville stoppe henne.

Nå har Saido totalt 16 søsken. Det kom tvillinger til slutt. Tvillingene og fem av de andre søsknene bor fortsatt sammen med foreldrene i Stjørdal.

- Foreldrene mine har alltid støttet oss. Og vi søsknene har vært nære som bestevenner. Min mor stilte med omsorg og varm mat hver dag når vi kom hjem fra skolen. De har pushet alle oss til å tenke utdanning. Jeg tror de vil bli skuffet hvis noen av barna ikke tar høyere utdanning, sier hun, og forteller at moren stadig gjentar at det viktigste er at barna skal være lykkelige.

\section{Jobbing ved siden av}

Til tider kunne det være vanskelig for Saido å finne sin plass blant alle de norske. Hun sier ikke så mye om sine egne opplevelser, men angir at de unge som ikke likte seg på ballspillbanen, kunne ha det tøft. Saido tok kontakt med Kulturverksted for ungdom i Stjørdal. De arrangerte matlagingskurs, debatter, foredrag og kulturinnslag. Deretter ble 
det verv i det lokale Røde Kors. Da lederen i Røde Kors ble skutt på Utøya, tok hun over lederrollen. I moskeen har hun aldri vært særlig engasjert. Ingen i familien har krevd det.

Samholdet i familien og blant de andre somalierne i Stjørdal har vært helt avgjørende for at jeg har det så bra

Helt fra ungdomstida har hun jobbet, i helgene og i skoleferiene. Første jobb var å selge helgeutgavene av VG på dørene til folk i småbyen. Så ble hun leksehjelper for enslige mindreårige, jobbet på et bosenter, på distriktmedisinsk senter og etter hvert på Slagenheten på St. Olavs hospital i Trondheim. Hun har alltid møtt opp personlig når hun har vært ute etter ny jobb.

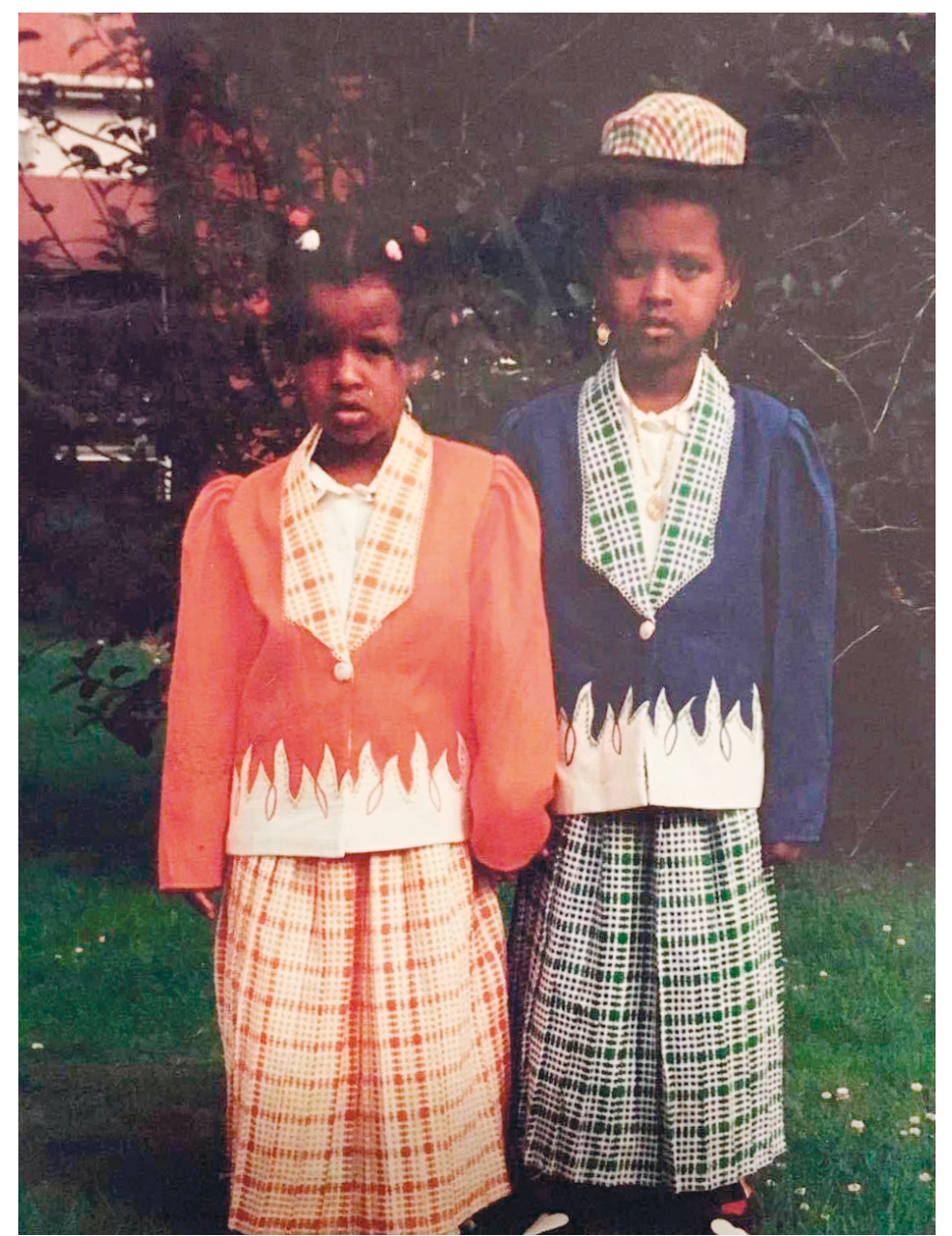

Søstrene etter at de kom til Stjørdal fra millionbyen Mogadishu. Saido i rødt og Maryam i blått. Foto: privat

- En jobbsøknad med mitt navn på kan fort havne nederst i bunken, slår hun fast. En av somrene ble det tre jobber samtidig. Da var det vel travelt, men skussmålene var likevel alltid gode. Slike bekreftelser har gitt henne stadig større trygghet.

\section{Utdanning i Polen}

- Jeg var et godt stykke fra å komme meg inn på medisinstudiet i Norge. Hadde jeg visst hvor tøft de første årene i Polen skulle bli, hadde jeg heller tatt opp fag fra videregående, slår hun fast.

- To av tre studenter som startet på utdanningen i Polen, har gitt opp eller ikke klart eksamen. Det er rått at man tar inn så mange studenter uten at de vet hva de går til og uten å ha plass til alle i praksis på sykehusene. Universitetene tjener masse penger på dem før de slutter.

- Og hva med å gå med hijab i Polen?

- Da jeg flyttet til landet, var det ikke noe problem. Det er jo egentlig mange i den eldre 
generasjonen i Polen som bruker ganske tildekkende sjal. Sånn sett var det ikke så annerledes med meg. Men etter terroranslagene på strandpromenaden i Nice i 2016 og andre påfølgende terroraksjoner ble det annerledes i Polen.

En jobbsøknad med mitt navn på kan fort havne nederst i bunken

Hun trekker litt på det. Ser litt ned. Alvoret kommer over det ellers blide ansiktet.

- Jeg vil helst ikke snakke om det. Folk er så forskjellige, og jeg vil ikke skjære alle over en kam. På Universitetet er det i alle fall ikke noe problem å gå med hijab.

Saido er opptatt av rettferdighet. Sommeren mellom 4. og 5. studieår kom hun med på NorPal-Sawa, et samarbeidsprosjekt der norske og palestinske studenter møtes i Nablus på Vestbredden. Da Saido var der, var temaet mor-barn-helse. Nå er hun koordinator for det samme prosjektet. Ti norske studenter får hvert år $\emptyset$ konomisk st $\varnothing t t e$ fra Legeforeningen. De resterende utgiftene betaler legestudentene selv.

- Det var vi som lærte av palestinerne, ikke omvendt. Få med det! sier hun bestemt.

Saido gleder seg til å mimre fra oppholdet i fjor.

- Jeg skal nemlig reise over Vestfjorden til Svolvær for å ha en helg sammen med en av de andre som var på Vestbredden i fjor.

Den andre har fått jobb på et legekontor i Lofoten.

- Det blir gøy å komme enda lenger ut i havet!

\section{Rollemodell og legehverdag}

Saido blir synlig rørt når jeg videreformidler at helsesykepleieren i kommunen mente at hun har blitt et forbilde for de somaliske jentene i kommunen. Hun har nok skjønt det selv også. En liten guttepjokk som åpenbart var fra Somalia, stoppet henne på den lokale butikken. Han ville vite om hun var den nye somaliske legen. Da han fikk bekreftet det, løp han etter sin litt større storebror. Begge ville hilse på legen som tydeligvis hadde vært et samtaletema i hjemmet. Saido forteller historien med blanke øyne, før hun mer nøkternt skildrer hverdagen på legekontoret.

- I sentrale strøk er det så lett å sende pasientene til spesialister. Her tar det nesten fire timer i bil før du kommer til sykehuset. Jeg drøfter pasientene med kollegaene her på kontoret. Om nødvendig konfererer vi med sykehuset om resultater og funn. Det å jobbe slik er skikkelig spennende.

Legene på kontoret er behjelpelige når sommervikaren står fast. Og de henter henne når pasienter har sjeldne sykdomstilstander. Slik sikrer de erfarne at den nye legen lærer mest mulig. Allerede før Saido startet, visste de at hun var ivrig og lærenem. Hun tok nemlig selv initiativet til å hospitere på legekontoret i tre uker rundt påsketider. Kollegiet konkluderte med at hun var en egnet kandidat for sommerjobben - til tross for at hun kun har midlertidig legelisens.

\section{Ny vår på Hamarøy}

Saido avsluttet sommerferien i fjor med en ferietur til Dubai sammen med søsteren.

- Vi feiret at søsteren min, Maryam, var ferdig utdannet jordmor. Hun nøyde seg ikke med sykepleierutdannelse, slik hun skrev under på lappen i 2008, fortsetter Saido stolt. 


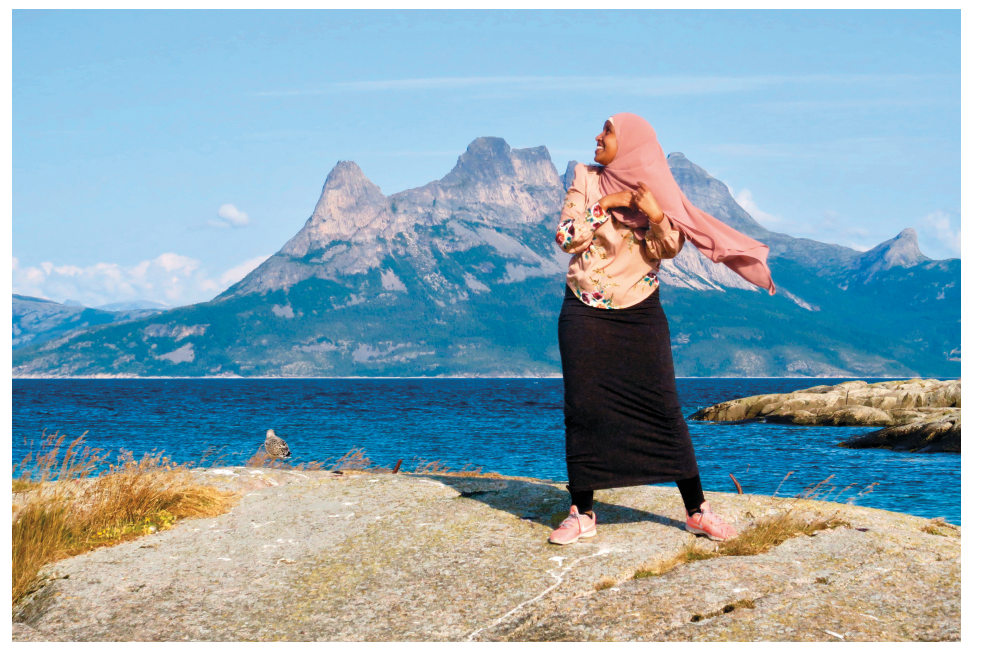

Saido elsker å oppleve nye landskap. Hun lar seg ikke skremme av en måke som vil ha henne vekk. «Du vet-jeg har ikke vart lenger nord enn Levanger tidligere. Å få oppleve dette er en ekstra bonus med jobben!» Foto: Tori Flaatten Halvorsen

Saido fikk dessverre ikke vært med på festen som de somaliske kvinnene i Stjørdal arrangerte for søsteren i fjor høst. Legestudenten kunne ikke ta seg tid til det. Sisteåret på studiet har vært det aller tøffeste. Selv i julen hadde kollokviegruppen i Polen daglige samlinger. Da visste hun ikke at siste del av eksamenslesingen skulle skje samtidig med at hun igjen var vikarlege på Hamarøy.

Hadde jeg visst hvor tøft de første årene i Polen skulle bli, hadde jeg heller tatt opp fag fra videregående

- Nå er det bare den siste eksamenen igjen, én skriftlig og én praktisk del. Ingen vet når vi får komme tilbake til Polen for å ta den indremedisineksamenen.

Saido virker verken frustrert eller særlig irritert under telefonintervjuet, som finner sted skjærtorsdag. I stedet skildrer hun hvordan det blåser rett mot de store panoramavinduene som gir utsikt mot havet.

- Jeg har fått låne den kjempefine hytta til foreldrene til kommunelegen. Det er jo hytteforbud, så da kunne jeg få flytte inn, kvitrer hun.

- Men hvordan kommer du deg på jobb i kommunesenteret Oppeid? Hytta er jo ganske avsidesliggende.

- Det kan du si! I morges satte jeg meg fast med bilen i nysnøen. Folkene fra kommunen måtte taue meg ut, ler Saido.

\section{Juni - ferdig lege}

Vi nærmer oss sankthans, og det er tid for en oppsummering via Skype.

- Nå er jeg helt ferdig. Sensuren falt i går. Alt gikk bra! Stemmen til Saido er lett. Det store smilet og de levende øynene hennes dekker hele skjermen. Hun forteller at fakultetet på universitetet arrangerte netteksamen for studentene som satt rundt $i$ hele verden. Først var det skriftlig indremedisinsk eksamen med flervalgsoppgaver (multiple choice). Etter en halvtimes pause gikk studentene over til en praktisk eksamen som også foregikk over nettet.

- Så du satt hjemme i Stjørdal?

- Neida, jeg er faktisk her i leiligheten i Polen. Eksamen og pakking samme uke.

- Men hvordan kom du deg dit?

- Fly fra Norge til Amsterdam. Flyet videre ble kansellert. Så da ble det buss. På grensen mellom Tyskland og Polen måtte jeg vise fram papirer fra Universitetet, slik at grensevaktene kunne slippe meg inn. Så var det temperaturmåling. Heldigvis ingen feber! 
- Og hva gjør du nå?

- Jeg pakker ned klær og noen få ting som betyr noe for meg. En svensk-somalisk tredjeårsstudent skal flytte inn her. Hun tar over det meste av tingene mine.

Saido forteller at det er trist at hun ikke fikk sagt ordentlig adjø til alle medstudentene, som nå er mer eller mindre isolert rundt om i hele verden.

- Men de som befinner seg her, skal samles for en privat, liten avslutning. Vi har til og med bestilt oss blå graduate-uniformer og fotograf.

- Så hvor skal du i turnus da?

- Jeg har fått tilbud om to turnusplasser. Det kan se ut til at jeg skal hjem til Trøndelag, sier Saido fornøyd.

Publisert:13. august 2020. Tidsskr Nor Legeforen. DOI: 10.4045/tidsskr.20.0544

(C) Tidsskrift for Den norske legeforening 2020. Lastet ned fra tidsskriftet.no 